\title{
Safety and Performance Evaluation Method for Wearable Artificial Kidney Systems
}

\author{
YeJi Ho ${ }^{1}$, SangHoon Park ${ }^{2}$, KyungMin Jo ${ }^{3}$, \\ Barum Choi ${ }^{4}$, SangEun Park ${ }^{5}$ \\ Asan Institute for Life Sciences, Asan Medical Center, \\ Seoul, Korea
}

\author{
Jaesoon Choi ${ }^{6}$ \\ College of Medicine, University of Ulsan, Ulsan, Korea, \\ Asan Institute for Life Sciences, Asan Medical Center, \\ Seoul, Korea
}

\begin{abstract}
This paper focuses on international standards and guidelines related to evaluating the safety and performance of wearable dialysis systems and devices. The applicable standard and evaluation indices for safety and performance are determined, and the relevant international standards and guidelines are provided in a table. In addition, example experiments using a triaxial accelerometer and robot arm are presented for testing the endurance and safety of wearable artificial kidneys. The findings in this paper can be used to suggest new guidelines for the mechanical safety and performance evaluation of wearable artificial kidney systems.
\end{abstract}

Keywords-Wearable artificial kidney; safety; hemodialysis; peritoneal dialysis; accelerometer

\section{INTRODUCTION}

As lifestyle-related metabolic disorders such as diabetes and hypertension continue to proliferate with westernized diets, the number of patients with end-stage kidney failure has drastically increased. When end-stage kidney failure is caused by diabetes, which is most frequently the case, the 5-year survival rate is only $50 \%-60 \%$. This is much lower than the rates for stomach cancer and colorectal cancer. In the USA, approximately 45,000 people died of end-stage kidney failure in 2006; it is ranked as the ninth-leading cause of death among Americans.

According to the organ transplant status provided by the Korea Organ Network for Organ Sharing (KONOS) and US Department of Health \& Human Service, the number of patients waiting for kidney transplants soared between 2000 and 2015, but actual cases of kidney transplants increased only slightly. Because the supply is far less than the demand for kidney transplants, the majority of patients are treated with dialysis therapy. In the medical device industry, the hemolysisrelated market reached 75 billion USD in 2011 and is continuing to grow each year.

Until now, the hemolysis-related market has been focused on supplying equipment and consumables. However, total renal care service-integrating the complete process of hemolysis including management, service, and remote therapy-is expected to dominate the future market. A representative example of this trend is the self-dialysis unit for home use.

This research was supported by grants (No. 15172MFDS434 and No. 17172MFDS340-4) from Ministry of Food and Drug Safety in 2015 and 2017.
Around the world, about $11 \%$ of patients treated with peritoneal dialysis and $0.6 \%$ of those treated with hemolysis have been reported to stay at home for therapy. This indicates the rapid growth and increasing use of home-use self-dialysis units [1], [2]. The entire market related to artificial kidney and hemolysis is expected to rapidly grow.

New types of wearable artificial kidneys for patients with end-stage kidney failure are being actively developed [3]-[9], however there are no criteria available for evaluating the safety and performance of wearable artificial kidneys. In this study, existing local and overseas standards and guidelines were analyzed, and evaluation indices were derived. A safety and performance evaluation method is proposed for new types of wearable artificial kidneys.

\section{STANDARDS FOR SAFETy AND PERFormanCE EVALUATION}

\section{A. New Types of Wearable Artificial Kidneys}

In most advanced countries, portable artificial kidney devices are classified as wearable or home-use types according to their purpose and place of usage. Home-use artificial kidney devices share common characteristics, but small artificial kidney devices are portable. Accordingly, the latter group was set as a single category, and the following three types were considered in this study: wearable, house-use and portable.

Artificial kidneys can be classified as house-use or portable types and have been already developed for self-dialysis or peritoneal dialysis at home. In addition, safety and performance evaluation systems for these artificial kidneys have been established. Thus, this study considered wearable artificial kidneys that can be used outside the hospital without the help of medical experts. With regard to common matters such as physiological functions, performance, and major safety considerations, the corresponding provisions in existing standards for other types of artificial kidneys (e.g., IEC, ISO, KS) were applied.

\section{B. International Standards and Guidelines Applicable to Wearable Artificial Kidneys}

Because there are no standard and guidelines for wearable artificial kidneys, international standards and guidelines for hemodialysis/peritoneal dialysis system and portable medical devices were evaluated if they seemed applicable to wearable artificial kidneys. Table I presents the international standards and guidelines. 
TABLE I. APPLICABLE STANDARDS AND GUIDELINES FOR WEARABLE ARTIFICIAL KIDNEY SYSTEMS

\begin{tabular}{|c|c|c|}
\hline \multirow{9}{*}{ International Standards } & Standard No. & Item \\
\hline & IEC 60601-2-16 & Hemodialysis \\
\hline & IEC 60601-2-39 & Peritoneal dialysis \\
\hline & IEC 60601-1-6 & Usability \\
\hline & IEC 60601-1-11 & Home healthcare environment \\
\hline & IEC 62366-1 & Usability engineering \\
\hline & IEC 60529 & Degrees of protection provided by enclosure (IP code) \\
\hline & IEC 60721-4-7 & Portable and nonstationary medical devices \\
\hline & ANSI/AAMI RD5 & Hemodialysis systems \\
\hline \multirow{7}{*}{$\begin{array}{l}\text { Guidelines and } \\
\text { National Standards }\end{array}$} & State (Regulation authority) & Contents \\
\hline & South Korea (MFDS) & 29 artificial kidney system \\
\hline & \multirow{2}{*}{ USA (FDA) } & Guidelines for industry and FDA staff: hemodialysis blood tubing sets \\
\hline & & Guidelines for hemodialysis delivery systems \\
\hline & Europe (EU) & EN 60601-2-16, EM 60601-2-39 \\
\hline & Japan (PMDA) & JIS T 0601-2-39, JIS T 3250 \\
\hline & China (CFDA) & YY 0053-2008, YY 0054-2010 \\
\hline
\end{tabular}

TABLE II. EVALUATION INDICES For SAFETy AND PERFORMANCE

\begin{tabular}{|c|c|c|c|c|}
\hline \multicolumn{3}{|c|}{ Evaluation indices } & Contents & Related standards \\
\hline \multirow{9}{*}{ Safety } & \multirow{5}{*}{$\begin{array}{l}\text { Transit: } \\
\text { operable and } \\
\text { portable }\end{array}$} & Vibration & Broadband vibration test & \multirow{2}{*}{$\begin{array}{l}\text { IEC 60601-1-11 } \\
\text { IEC 60068-2-64 }\end{array}$} \\
\hline & & Battery & $\begin{array}{l}\text { Check the backup power and } \\
\text { indication of state }\end{array}$ & \\
\hline & & Push & $\begin{array}{l}\text { Enclosures of ME equipment shall have sufficient rigidity to } \\
\text { protect against unacceptable risk }\end{array}$ & \multirow[b]{2}{*}{ IEC 60601-1 } \\
\hline & & Molding stress relief & $\begin{array}{l}\text { Enclosures of molded or formed thermoplastic materials shall be } \\
\text { constructed so that any shrinkage or distortion of the material is } \\
\text { due to the release of internal stresses }\end{array}$ & \\
\hline & & Shock & Shock test & $\begin{array}{l}\text { IEC 60601-1-11 } \\
\text { IEC 60068-2-27 }\end{array}$ \\
\hline & Alarm & $\begin{array}{l}\text { Alarm condition and } \\
\text { overlap mode }\end{array}$ & Normal operation under each condition & $\begin{array}{l}\text { 29. Artificial kidney } \\
\text { (IEC 60601-1-8) }\end{array}$ \\
\hline & \multirow{3}{*}{ IP code } & $\begin{array}{l}\text { First characteristic } \\
\text { numeral (hazardous parts) }\end{array}$ & Protection against access to hazardous parts & \multirow{3}{*}{ IEC 60529} \\
\hline & & $\begin{array}{l}\text { First characteristic } \\
\text { numeral (solid foreign } \\
\text { objects) }\end{array}$ & Protection against solid foreign objects & \\
\hline & & $\begin{array}{l}\text { Second characteristic } \\
\text { numeral (water) }\end{array}$ & $\begin{array}{l}\text { Test for second characteristic numeral } 2 \\
\text { with the drip box }\end{array}$ & \\
\hline Performance & \multicolumn{2}{|c|}{ Dialysis fluid temperature } & Measurement of the dialysis fluid temperature & $\begin{array}{l}\text { IEC 60601-2-16, IEC } \\
\text { 60601-2-39, YY 0054, JIS } \\
\text { T 0601-39 }\end{array}$ \\
\hline
\end{tabular}

The international standards for hemodialysis and peritoneal dialysis systems are IEC 60601-2-16 and IEC 60601-2-39, respectively. In this study, new types of wearable artificial kidneys were defined as medical devices used by patients, not medical experts. Accordingly, IEC 60601-1-11 should be applied for the home healthcare environment, including medical devices for home use and point of care. IEC 60601-1-6 and IEC 62366-1 should be applied for usability.

Apart from international standards, relevant guidelines and national standards were also surveyed. Both the Food and Drug Administration (FDA) and Ministry of Food and Drug Safety (MFDS) provide guidelines for hemodialysis based on IEC 
60601-2-16. Especially in the case of medical devices for the high-risk group, the innovation pathway of FDA allows some documents required for license to be submitted after the devices come to the market. This allows for a fast examination to issue a license. No wearable artificial kidneys have yet been licensed. In 2012, Gura et al.'s [3] wearable artificial kidney was the first to be permitted for clinical application. In Europe, Council Directives 93/42/EEC and 90/385/EEC for medical devices established the EN-60601-x standard based on the IEC 60601 series and enforce its observation.

In Japan (PMDA) and China (CFDA), the Japanese Industrial Standards and YY (medicine and medical device standard) of China Compulsory Certification are based on IEC 60601-2-16 and IEC 60601-2-39 and include additional requirements for matters such as special test methods.

\section{EVALUATION INDICES}

Common applicable indices for safety and performance evaluation were derived from the surveyed national standards and guidelines that seemed to be relevant to wearable artificial kidney. These are presented in Table II.

The safety evaluation indices included characteristics of transit-operable and portable devices, which are specified by IEC 60601-1-11 (home healthcare environment), alarm systems (IEC 60601-1-8), and waterproof/dustproof-related safety. A common performance evaluation index is the dialysis fluid temperature, but it appeared to differ by country and standard, so it was excluded from the evaluation indices in this study.

\section{EXAmPle Evaluation Methods}

The above safety and performance evaluation indices are based on existing standards for dialysis systems. Environmental tests such as vibration and shock tests for transit-operable and portable devices, which are specified in IEC 60601-1-11, do not seem to sufficiently consider the intrinsic features of wearable artificial kidneys. Accordingly, example methods for evaluating the durability and safety that consider the device features are presented below. A wearable artificial kidney being developed by a research team at Seoul National University was subjected to the evaluation methods. Because the artificial kidney is not completely developed, a dummy without internal dialysis circuits and sensors was used. A triaxial accelerometer experiment and trajectory experiment using a robot arm were applied as the example methods for evaluating the durability and safety. The triaxial accelerometer experiment was performed to identify the acceleration range acting on a device during activities of daily living such as walking, running, and climbing up and down stairs. The trajectory experiment utilized a robot arm for various trajectory movements such as vertically reciprocal, circular, and falling motions.

\section{A. Triaxial Accelerometer Experiment}

1) Purpose: As shown in Fig. 1, a subject wore the wearable artificial kidney around his or her waist. A triaxial accelerometer was used to detect the range of acceleration that could affect the wearable artificial kidney system during movements of daily living (e.g., walking, running, and climbing up and down stairs).

2) Method: Nine adult subjects wore a wearable artificial kidney and performed easy activities of daily living (walking, running, and climbing up and down stairs. As shown in Fig. 2, a triaxial accelerometer (MMA7260Q, Freescale Inc., Austin TX) was used to measure the acceleration acting on the dummy according to the movement of the hip joint. A shortdistance wireless transmitting and receiving module (Bluetooth 2.0, OpenbrainTech Inc., South Korea) was attached to transmit acceleration signals to the PC. Each subject wearing the artificial kidney dummy with inserted sensors conducted 10 rounds of $25 \mathrm{~m}$ reciprocal walking and running movements. In addition, the subjects also climbed up and down 13 stairs 10 times (Fig. 3). The acceleration was measured for the movements of the wearable artificial kidney dummy in the directions of the mediolateral, anteroposterior, and superoinferior axes (Fig. 4). The measured accelerations were saved with LabVIEW2013 (NI Inc., Austin, TX). The measurements were subjected to a fast Fourier transform (FFT) to identify vibrations of the dummy during each movement in the frequency domain.

3) Results: When the subjects wearing the artificial kidney dummy walked and climbed up and down stairs, the frequency distribution was concentrated between 0.9 and $2.1 \mathrm{~Hz}$ on average. When the subjects wearing the artificial kidney dummy ran, the frequency distribution was usually concentrated at $3 \mathrm{~Hz}$ and above (Table II, Fig. 5).

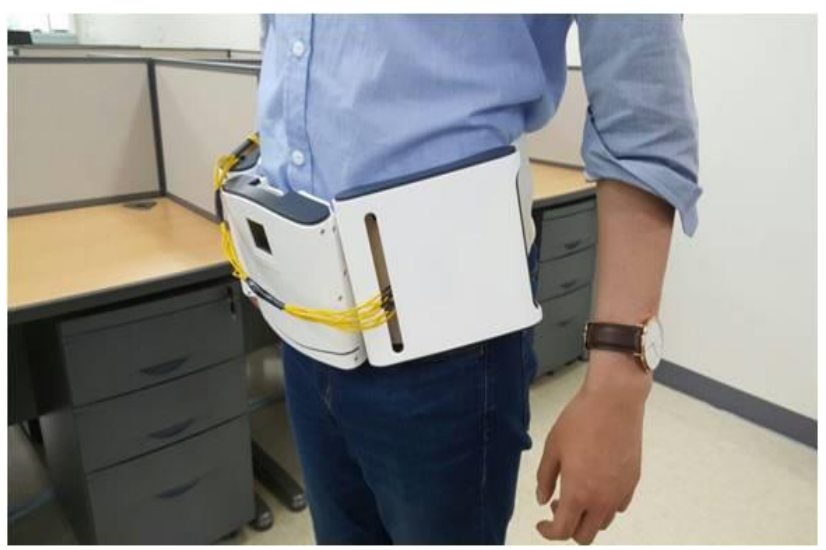

Fig. 1. Wearable Artificial Kidney System Dummy.
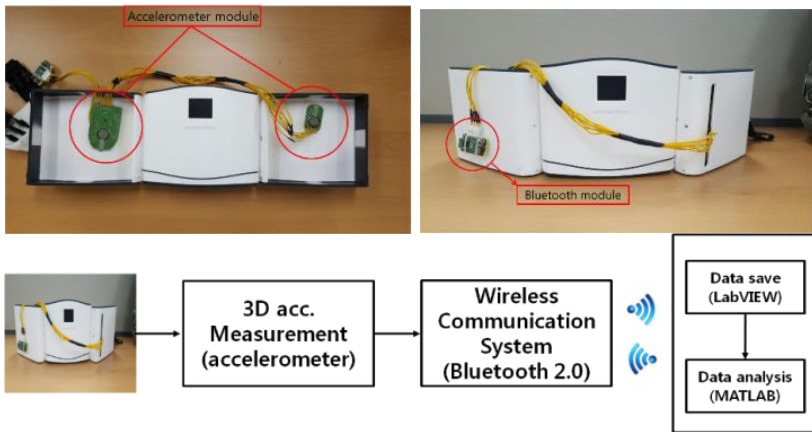

Fig. 2. Measurement System for the Triaxial Acceleration. 

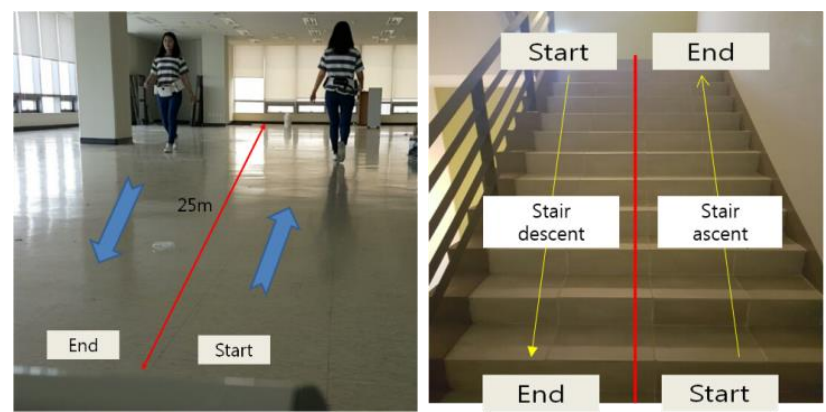

Fig. 3. Experimental Setup for Activities of Daily Living.
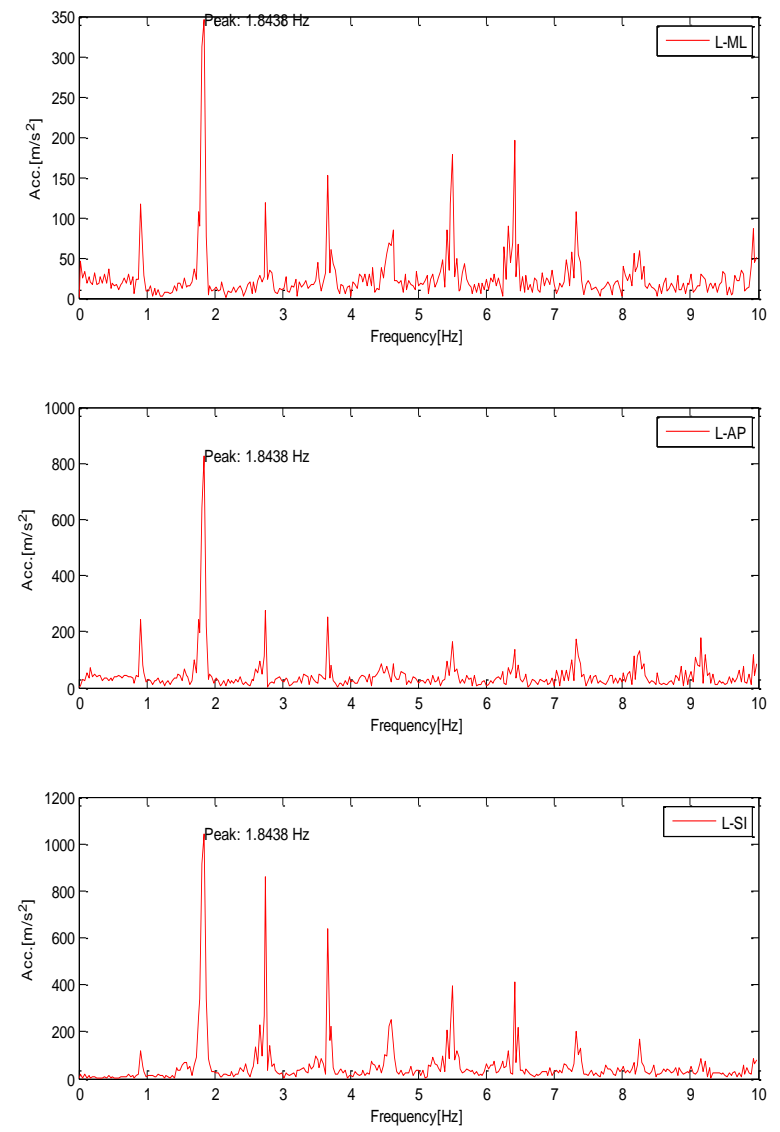

\section{(3)}

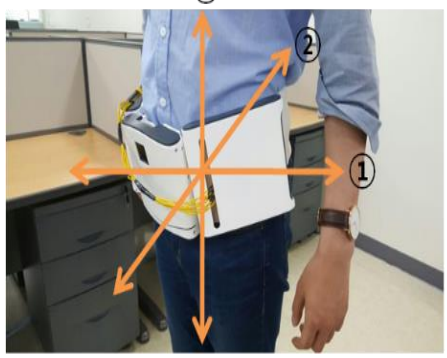

(1): Medialateral axis

(2): Anteroposterior axis

(3): Superoinferior axis

Fig. 4. Measurement Directions for the Triaxial Acceleration.
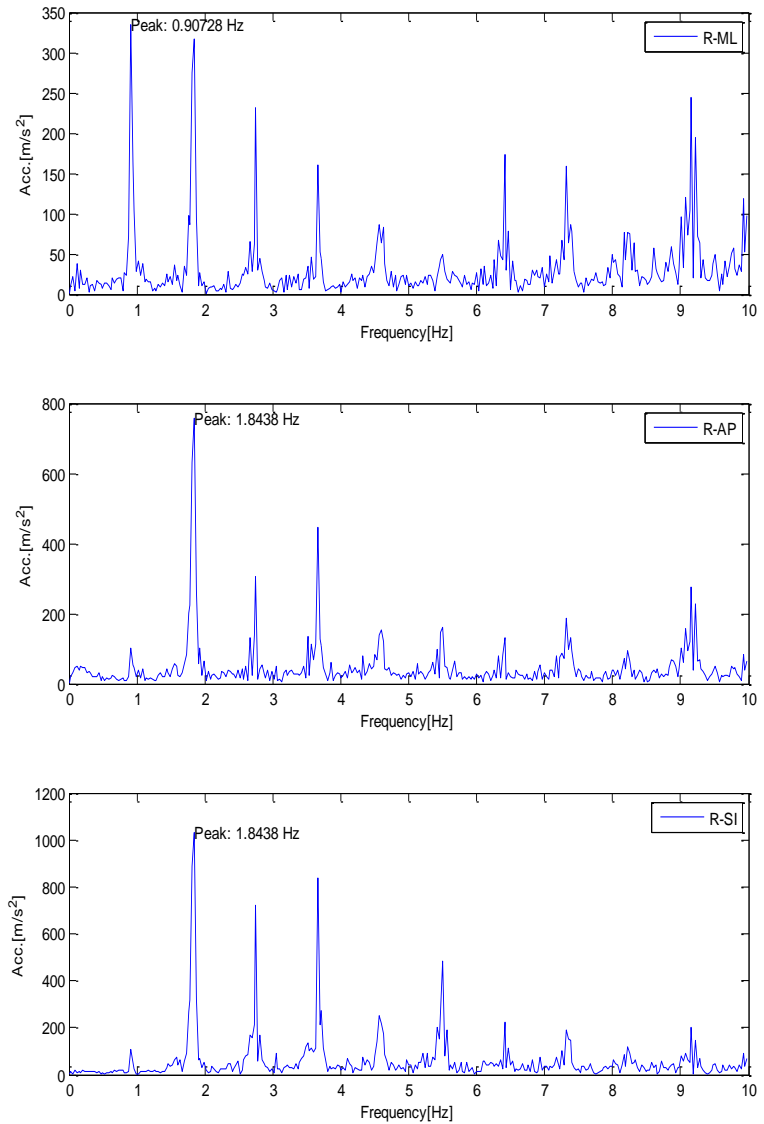

Fig. 5. Frequency Domain During Activities of Daily Living: Walking.

\section{B. Robot Arm Experiment}

1) Purpose: An experiment using a robot arm was performed to judge the normal operation of the wearable artificial kidney system during and after various trajectory movements like reciprocating vertical/circular/falling motions are repeated.

2) Method: As shown in Fig. 6, the wearable artificial kidney dummy was fixed to the robot arm (Hyundai Inc., Korea). The experimental conditions were set for vertical stroke, circular, and falling motions.

\section{CONCLUSION}

In this study, existing local and international standards and guidelines for dialysis systems and artificial kidneys were surveyed to propose a safety evaluation method for wearable artificial kidneys. The surveyed standards and guidelines were used to derive safety and performance evaluation indices that seem applicable to wearable artificial kidneys. Along with the evaluation methods specified by existing standards, example methods for evaluating the durability and safety are presented. A triaxial accelerometer or robot arm was applied to evaluate an artificial kidney dummy being developed by a Korean research team. 


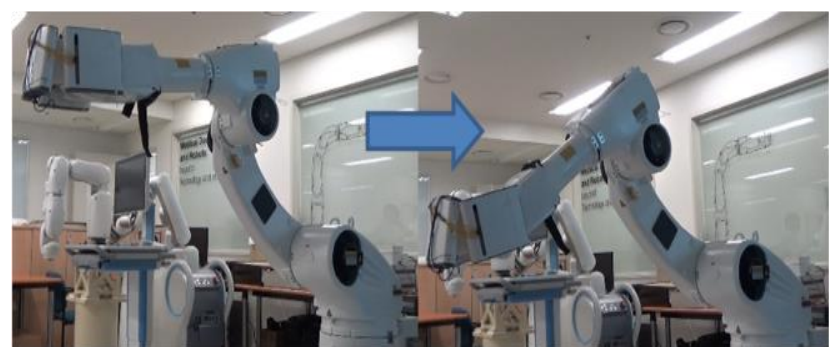

(a)

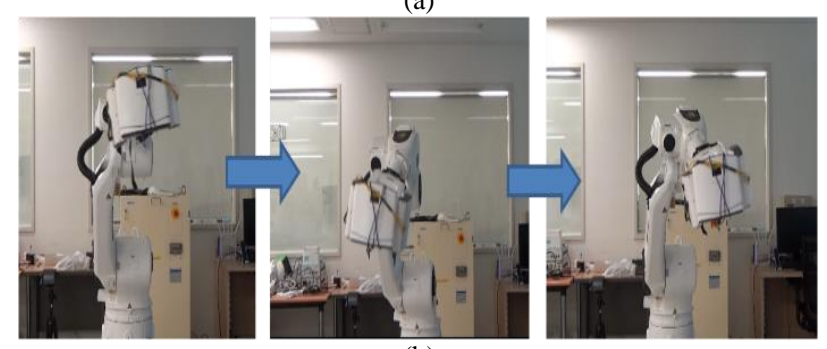

(b)

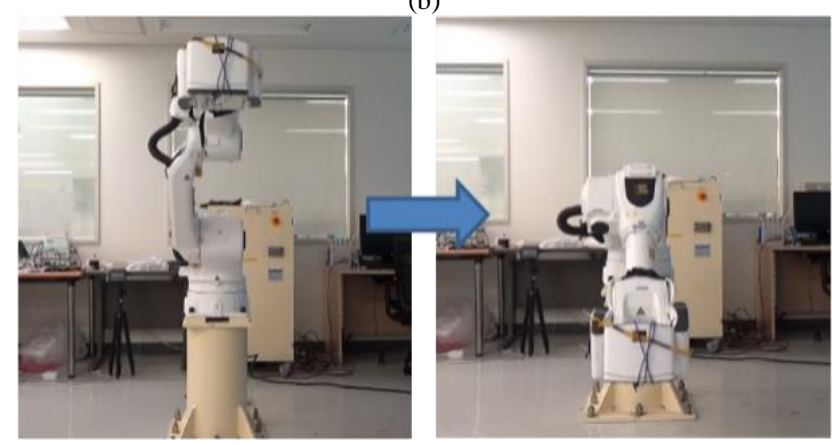

(c)

Fig. 6. Experimental setup for the robot arm trajectory: (a) stroke vertical motion (range: $400 \mathrm{~mm}$, speed: $270 \mathrm{~mm} / \mathrm{s}$ ), (b) circular motion (range: 400 $\mathrm{mm}(\mathrm{CCW})$, speed: $270 \mathrm{~mm} / \mathrm{s}$ ), and (c) falling motion (range: $1 \mathrm{~m}$, speed: 1.5 $\mathrm{m} / \mathrm{s})$.

Because the artificial kidney dummy does not include any internal dialysis circuits it cannot be considered a real artificial kidney system. Accordingly, even if the dummy was evaluated with the presented methods, its normal operation and safety could not be identified. Thus, the evaluation methods for durability and safety need to be applied to a prototype wearable artificial kidney that includes dialysis circuits and sensors. Future studies also need to check the normal operation and safety of a real wearable artificial kidney after evaluation. In addition, it should be performed additional daily activities such as sitting, lying down and falling [10]-[12], which were not performed in this study. If a motion capture system is used to measure the motion of the hip joint during each movement and the measurements are reflected in the trajectory experiment with a robot arm, the range of normal operation will be defined more effectively.

\section{REFERENCES}

[1] S. J. Shin, "Current status of bioartificial kidney," J. Biomed. Sci. Eng., vol. 7, pp. 108-111, 2004.

[2] J. C. Kim and C. Ronco, "Current technological approaches for a wearable artificial kidney," Contrib. Nephrol., vol. 171, pp. 231-236, 2011.

[3] V. Gura, A. S. Macy, M. Beizai, C. Ezon, and T. A. Golper, "Technical breakthroughs in the wearable artificial kidney (WAK)," Clin. J. Am. Soc. Nephrol., vol. 4, pp. 1441-1448, 2009.

[4] J. C. Kim and C. Ronco, "Personal daily dialysis: the evolution of the artificial kidney,” Blood Purif. J., vol. 36, pp. 47-51, 2013.

[5] J. C. Kim and C. Ronco, "The human nephron filter: toward a continuously functioning, implantable artificial nephron system," Blood Purif. J., vol. 23, no. 4, pp. 269-274, 2005.

[6] A. Davenport, "Portable and wearable dialysis devices for the treatment of patients with end-stage kidney failure: wishful thinking or just over the horizon?” J. Pediatr. Nephrol., vol. 30, pp. 2053-2060, 2015.

[7] A. R. Nissenson, "Bottom-up nanotechnology: the human nephron filter," Semin. Dial., vol. 22, no. 6, pp. 661-664, 2009.

[8] S. Takahashi, "Future home hemodialysis - advantages of the NxStage system one," Contrib. Nephrol., vol. 177, pp. 117-126, 2012.

[9] C. Ronco and L. Fecondini, "The Vicenza wearable artificial kidney for peritoneal dialysis (ViWAK PD)," Blood Purif. J., vol. 25, pp. 383-388, 2007.

[10] DM. Karantonis, MR. Narayanan, M. Mathie, NH. Lovell, BG. Celler , "Implementation of a Real-Time Human Movement Classifier Using a Triaxial Accelerometer for Ambulatory Monitoring" IEEE Trans Inf Technol Biomed., vol. 10, no. 1, pp 156-167, 2006

[11] MR. Narayanan, SR. Lord, MM. Budge, BG. Celler, NH. Lovell, "Falls management: detection and prevention, using a waist-mounted triaxialaccelerometer", Conf Proc IEEE Eng Med Biol Soc. Pp 40374040, 2007

[12] DW Kang, JS Choi, JW Lee, SC Chung, SJ Park, GR Tack, "Real-time elderly activity monitoring system based on a tri-axial accelerometer", Disabil Rehabil Assist Technol., vol. 5, no. 4, pp 247-253, 2010 